\title{
Technical Possibilities of Cloud-Based Virtual Reality Implementing Software as a Service for Online Collaboration in Urban Planning
}

\author{
Zhenjiang Shen1, Yan $\mathrm{Ma}^{2 *}$, Kenichi Sugihara ${ }^{3}$, Zhenhan Lei', Evan Shi ${ }^{5}$ \\ ${ }^{1}$ School of Environmental Design, Kanazawa University, Kanazawa, Japan \\ ${ }^{2}$ Institute of Geographic Sciences and Natural Resources Research, Chinese Academy of Sciences, Beijing, China \\ ${ }^{3}$ Gifu Keizai University, Ogaki, Japan \\ ${ }^{4}$ Forum 8 Inc., Tokyo, Japan \\ ${ }^{5}$ Department of Computer Science, University of California, Los Angeles, USA

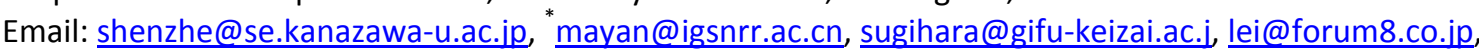 \\ eshi@ucla.edu
}

Received 12 September 2014; revised 20 October 2014; accepted 3 November 2014

Copyright (C) 2014 by authors and Scientific Research Publishing Inc.

This work is licensed under the Creative Commons Attribution International License (CC BY).

http://creativecommons.org/licenses/by/4.0/

c) (i) Open Access

\begin{abstract}
In this paper we discuss the technical possibilities of cloud-based virtual reality (cloud-based VR) computing tools for online collaboration in urban planning and design. We first create a digital asset representing our design proposal of a pedestrian bridge in Shibuya, Tokyo. A platform for cloud-based VR technology, i.e., a VR-Cloud server, is used to open the VR dataset to public collaboration over the Internet. The digital asset representing the design scheme of our pedestrian bridge includes buildings, roads, trees and street furniture for the entire urban area. The vehicles and people are designed and inputted into the virtual world of the urban area, in which they run and walk with predefined behaviour scenarios. Users share the VR world by accessing the VRCloud servers from remote clients, using cloud communication software to review vehicle and pedestrian crowd simulations and discuss the design concepts. Meanwhile, we compare the advantages and disadvantages of three cloud-based VR tools on their technical support for net collaboration: 1) VR-Cloud; 2) Google Earth; and 3) 3DVIA.
\end{abstract}

\section{Keywords}

VR-Cloud, Design Coordination and Communication, Server, Digital Asset and Pedestrian Bridge

\footnotetext{
${ }^{*}$ Corresponding author.
}

How to cite this paper: Shen, Z.J., Ma, Y., Sugihara, K., Lei, Z.H. and Shi, E. (2014) Technical Possibilities of Cloud-Based Virtual Reality Implementing Software as a Service for Online Collaboration in Urban Planning. Int. J. Communications, Network and System Sciences, 7, 463-473. http://dx.doi.org/10.4236/ijcns.2014.711047 


\section{Introduction}

In this paper we contribute an application of cloud-based virtual reality (cloud-based VR) for online collaboration in designing a pedestrian bridge in Japan by proposing design alternatives, and understanding and deliberating design concepts through the Internet. Cloud computing is a marketing term for technologies that provide computation, software, and storage services that do not require end-users' knowledge of the physical location and configuration of the system that delivers these services. The underlying concept of cloud computing could be dated back to the 1950s when large-scale mainframe computers became available in academia and corporations. Since 2007, cloud computing has attracted great interest from the information and communication technology field and facilitated numerous industry developments [1]. It was correspondingly defined as a type of parallel and distributed system providing virtualized resources in a pay-as-you-go fashion over the Internet [2]. Cloud computing exhibits the following key characteristic: device and location independence [3] enables users to access systems or an application using a web browser, regardless of their location or what device they are using. As infrastructure is off-site and accessed via the Internet, users can connect from anywhere and anytime for their service. In the case of online collaboration, users can employ cloud-based VR system in a participative process, and the cloud-based VR technology can serve as a software tool for planning to publish design proposals, and for stakeholders to share designs and communicate with each other to reach mutual goals through the Internet.

Cloud computing is divided into multiple service categories, which are data as a service (DaaS), software as a service (SaaS), application programming interfaces as a service (APIaaS) and platform as a service (PaaS). We will introduce how we use SaaS to share design concepts between designers and stakeholders in order to efficiently reach a consensus on project goals. To discover the most suitable platform and software for a variety of users, we will compare relevant differences between software and analyze their technical capabilities and user experience in online collaboration.

Modern researches taking advantage of cloud computing technology are increasingly prevalent in a great range of today's scientific journals. Researchers in information science use the technology to establish sustainable information services [4]. As the utilization of smart phones quickly spread, mobile cloud computing appeared and made a number of applications and services available on mobile devices [5]-[9], providing improved infrastructure and service for big data collection and research [10] [11]. Driven by its scalability, reduced costs, and easy access, cloud computing is also popular in geoscience research and applications [12]-[14]. In short, cloud computing is popular in various fields of research due to its great potential in sharing resources between local computers with other computing devices over the Internet.

As Couclelis described, urban planning is an increasingly complex endeavor and parties involved should embrace all the help they can get to deal with its complexity [15]. Thus, planning support systems (PSSs) appeared to offer such support. Conventional planning support systems are developed based on an object-oriented approach both in the local environment and the Internet environment. Spatial database systems, such as the geography information system (GIS) and virtual reality (VR), are essential components of planning support systems.

However, PSS databases are usually very big, requiring a high quality PC to run the designed PSS locally. A solution in conventional planning support systems involves saving the database to a local computer for urban management or saving the database to a server site for stakeholders to review. With the advent of cloud computing, there are many possible implementations of this solution. For example, DaaS can be used to share data between designers and planners [16] [17]; SaaS can be used to coordinate designs and communicate between stakeholders [18] and APIaaS can be provided for users to develop planning support tools via the Internet [19]-[22]. Furthermore, it is possible to integrate DaaS, SaaS and APIaaS for collaborative planning [23] [24] or transportation research, such as using cloud computing devices in cars to communicating with the external environments, or with other cars, or both [25].

Virtual reality programs such as Second Life and Active Worlds show that it is possible to share the virtual world of urban design over the Internet, an important aspect of using VR to support planning. There are already many studies based on VR or 3DGIS. For example, Shen and Kawakami [26] [27] at Kanazawa University in 2010 finished an online visualization tool for Internet-based townscape design and discussed the roles of VRML in design proposals and visualizations of townscape rules. They also reported on research [28] [29] using Google Earth and 3DVIA as a VR system, similar cloud computing SaaS for coordinating and communicating designs. 
Contemporary planners who use cloud-based VR technology like Google Earth and 3DVIA will find it easy to change 3D objects to represent alternative designs. Most of the conventional VR tools also provide functionality to exchange 3D datasets rather than editing 3D objects. However, users should develop their own tools in order to realize the possibility of exchanging design alternatives. Cloud-based VR technology provides SaaS for users to employ the tools provided by the service to coordinate and communicate with stakeholders through the Internet. Therefore, SaaS for VR like 3DVIA can provide users the function to edit 3D databases. At the same time, 3D datasets are difficult to edit over the Internet because of the size of the data. Due to this limitation, it is challenging to engineer a VR data or 3D dataset service, e.g. DaaS for designers or stakeholders in PSS to allow collaboration on design concepts with real data, instead of presenting the design schemes. However, it is not necessary for designers and stakeholders to employ cloud-based APIaaS or PaaS to develop any tools for on-field use. In our present work, we will use a cloud-based VR system to provide the SaaS for sharing the virtual world with other users. As a demonstration of collaborative design, users can use the SaaS to review the virtual world by examining the design's alternatives. During this process users can also communicate with each other and finally give feedback to the designers. DaaS, PaaS and APIaaS are not used by professional designers and planners in real-time work; instead it is only used for representation of design alternatives.

The structure of this paper is as follows. In Section 2, we will discuss how to promote the use of a cloudbased VR tool in online collaboration. In Section 3, we will present 3 cloud-based VR tools that allow users to propose and share design alternatives on the Internet for deliberation. In Section 4, we will complete the paper with conclusions and discussions regarding the different types of cloud-based VR tools. Finally, we will discuss future works.

\section{Research Approach}

Our research approach is mainly divided into three parts. First, we use cloud-based VR technology to allow users to share a design of a pedestrian bridge with a convential VR database. We will not discuss the details of DaaS, APIaaS, PaaS and SaaS, which are the different services provided by cloud-computing technology. However, we will investigate the collaborative potential of SaaS in implemented with the different cloud-based VR tools presented in this work. We import the bridge design's dataset into three cloud-based VR software systems serving as SaaS (VR-cloud, Google Earth, and 3DVIA) for coordinating and communicating on the design. Second, we will focus on comparing the SaaS provided by the three systems and discuss the applications of cloud computing in design coordination and communication. Finally, we present a conclusion evaluating which SaaS implemented using cloud-based VR tools is most suitable to collaborative urban planning.

\section{Cloud-Based VR in Different Platforms}

We use three tools to explore the collaborative potential of cloud-based VR SaaS:

1) VR-Cloud v2.0, VR database created in the format of UC-Win Road Ver.5.02.03 and BIM Software All Plan 2011.

2) Google Earth Version 6. VR database created in the format of Google SketchUp 8 and Google 3D warehouse.

3) 3DVIA. VR database created in the format of 3DVIA player.

We then complete a pedestrian bridge design located in Shibuya, Tokyo as a case study, and input the dataset of the our design propose into the three tools.

a) VR database and VR representation

Design coordination and collaboration between stakeholders via the Internet usually requires a VR database, a VR visualization tool and a means of communication.

DaaS is necessary to maintain a VR database in which user can upload and manage the database. All products we are evaluating, namely VR-Cloud, Google Earth and 3DVIA provide DaaS. In all three implementations, including Google Earth, the VR database is a file saved on a remote VR-Cloud server where the design can be reviewed. 3DVIA provides the possibility to upload 3D objects requires users to compile all 3D objects into one file for upload as well.

As SaaS, only 3DVIA products can provide functionality for editing 3D objects as a software service of its cloud-based VR system. There are no such editing functions in the platforms of Google Earth and VR-Cloud. While Google Earth and VR-Cloud can be downloaded and installed as local software for VR representation, 
3DVIA is a HTML-based web application accessed via HTTP. Any end user can upload data from remote clients to the VR dataset server if using the Google Earth or 3DVIA platforms. But VR-cloud only permits developers to manage the VR database from the back-end server side.

b) VR collaboration

To our knowledge, there are no software tools combining all functions of VR and communication into one platform. As an alternative solution for such a platform, we paired VR-Cloud, a product of FORUM8 Inc. and $\mathrm{QQ}$, a product of Tencent Inc. to match the requirements of our present study. VR-Cloud is employed as a cloud-based VR tool for visualizing the design alternatives and QQ is used as a communication tool between collaborators. QQ can be used for sharing online group discussions between multiple members during a meeting. QQ's multi-user video chat tool and remote client access tool will be used for reviewing designs. Other voice chat applications with photo and video sharing such as those developed by WEIXIN can be used too. Using the combination of these tools allow us to collaborate online and reach mutual goals on all the details of our urban design. Like VR-Cloud, 3DVIA and Google Earth also do not provide integrated communication tools.

For coordinating and communicating on urban designs, it is a great advantage if screen sharing is enabled or avatars can communicate peer-to-peer in the virtual world to confirm the design on the same area. VR-Cloud enables users to share their screens with collaborators over the Internet while Google Earth and 3DVIA do not enable screen sharing. However, 3DVIA supports Internet avatars representing the real members attending a meeting. Google Earth and VR-Cloud do not support avatars. Therefore, Google Earth, VR-Cloud and 3DVIA are not yet perfect products in terms of cloud-based VR tools for collaboration.

As we compare the collaborative SaaS functionalities provided by these three software tools, we emphasize several points: VR representation and visualization, and VR communication in multi-user environments. To investigate the potential cloud-based VR technologies have in the collaborative process of urban planning and design, we will take into account the strength of their VR representation and communication tools. However, the three software tools presented here have no strong functionality in peer-to-peer communication in multi-user environments. We will now compare the advantages and disadvantages of these three software tools.

\section{VR Representation and Communication as SaaS of the Three Tools}

The three tools actually use the same VR dataset created by Google SketchUp (Figure 1), converted into the suitable format for each tool. In this section, we will discuss the differences in the SaaS implemented by the three tools.

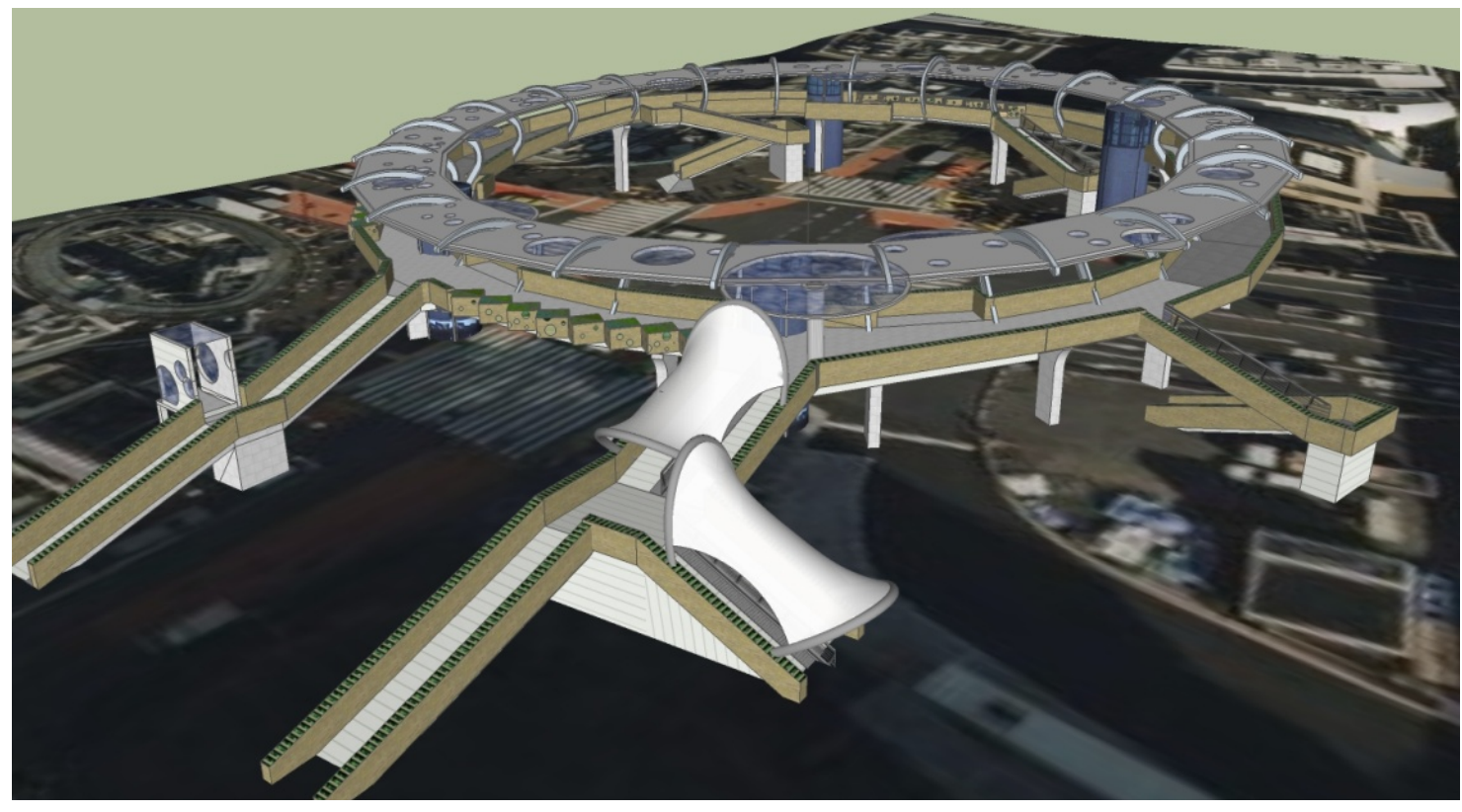

Figure 1. Bridge design edited in SketchUP and exported to 3DS or KMZ format for VR-Cloud, Google Earth and 3DVIA use. 


\subsection{VR-Cloud}

Like Google Earth and 3DVIA, VR-Cloud makes it possible to share its VR services with the world via the Internet. Specifically, clients communicate with its web servers via using conventional HTTP. Unlike Google Earth and 3DVIA, VR-Cloud does not implement true cloud servers-its application server cluster is accessed via specified static IP addresses respectively.

Even though the underlying dataset used in the three platforms is the same, we prepared an independent database compatible with VR-Cloud. Google Earth and 3DVIA use 3D warehouses to support their VR worlds. Importantly, Google Earth provides a unique virtual globe, making it much more convenient for its users to access the urban planning in other cities of the world by comparison.

As shown in Figures 2-4, VR-Cloud provides a comprehensive software service to support urban planning and design. In Figure 2, a user can share the screen and control the virtual perspective with other users in order to collaborate on specific location planning issues. Users of Google Earth and 3DVIA are not able to share the screen in remote planning meetings. In Figure 3, navigation functions are available to the user to control important traffic routes. VR-Cloud allows users to program specific simulated behaviors of individuals and cars in the virtual world. Traffic and ambient noise can also be simulated when users experience the VR world through different perspectives (Figure 4).

As mentioned above, the underlying VR dataset is the same in all three platforms. As demonstrated by Figures 2-4, VR-Cloud provides comprehensive functionality for navigating virtual worlds and simulating traffic. Meanwhile, Google Earth is designed as a virtual globe, using a technology called 3DGIS that contains geosurface and 3D structure databases. In the next section, we will focus on the SaaS functionality of Google Earth.

\subsection{Google Earth}

We used Google SketchUp to export the VR dataset into the KMZ format compatible with Google Earth. Google Earth, is already widely popular as free virtual globe software with users in the world. It is very convenient for users of Google Earth to share urban plans and designs with other users around the world, taking

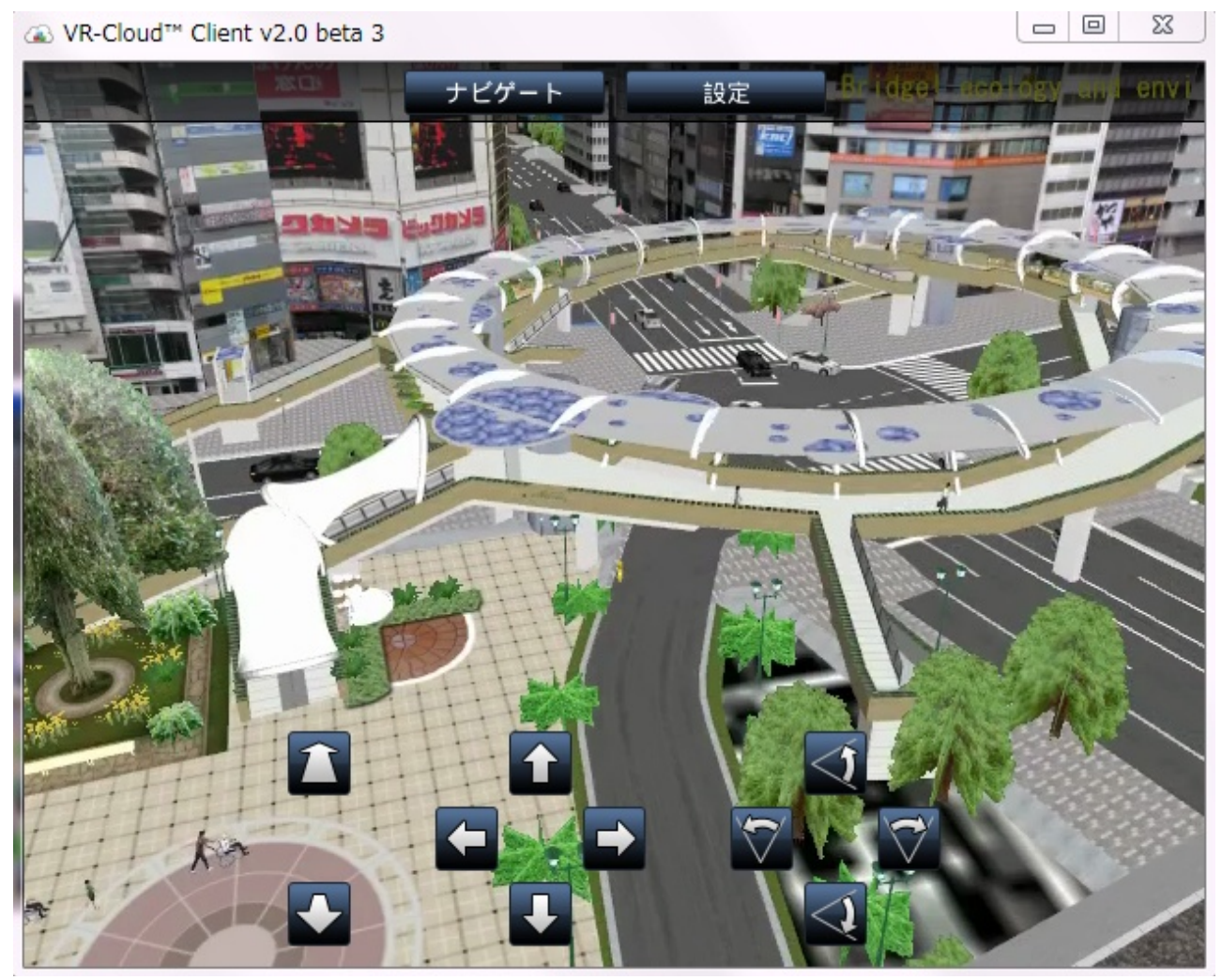

Figure 2. Bridge design in VR-Cloud. 

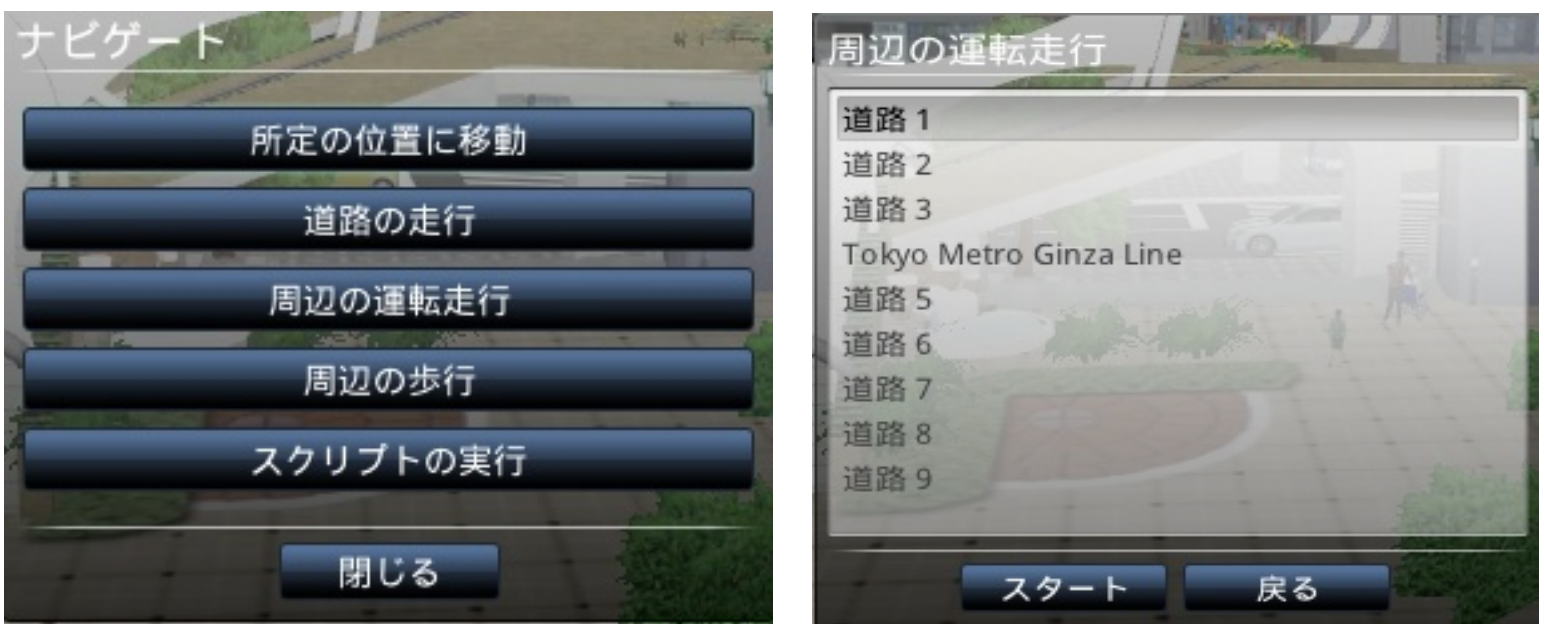

Figure 3. Interface of VR-Cloud (left: running route; right: option is different route).
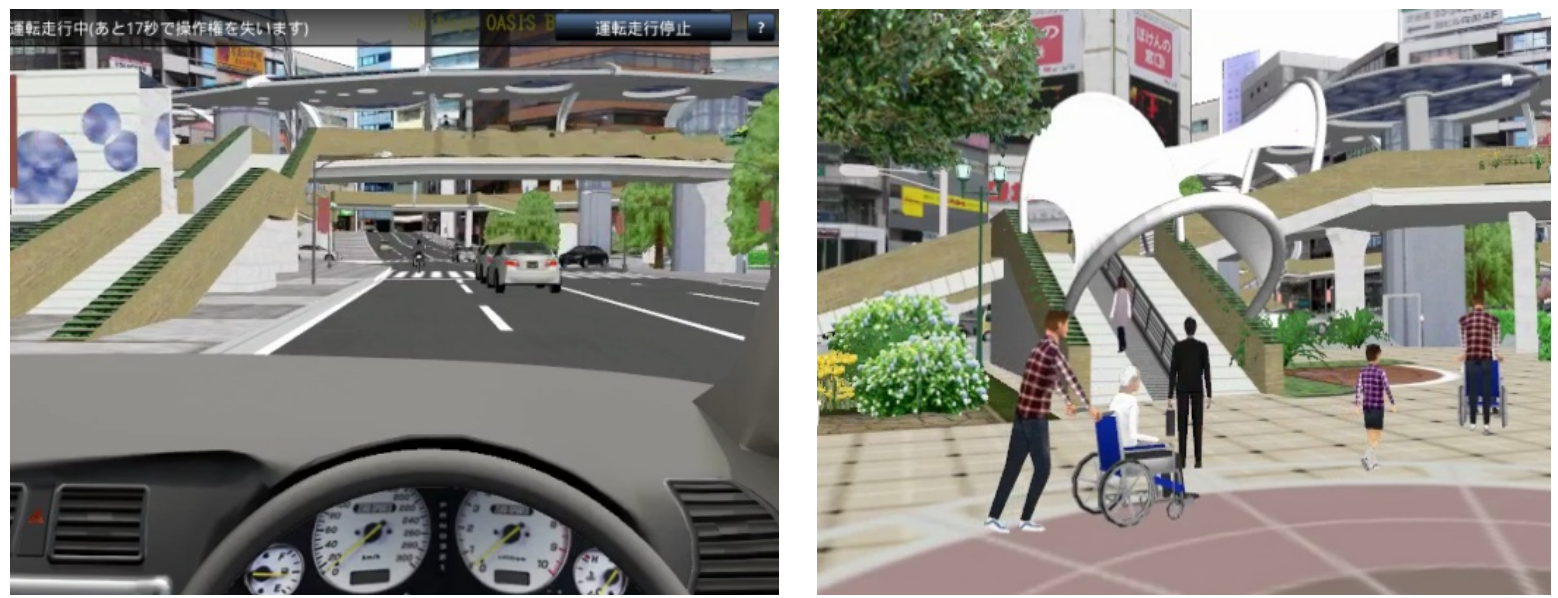

Figure 4. Shared screens in multiuser environment (left: car mode; right: pedestrain mode).

advantage of the virtual globe such that users can experience the dataset in the context of the entire virtual Earth as shown in Figure 5.

Google Earth provides some elaborate tools for experiencing its VR world. However, our objective is to be able to present design alternatives and it is currently impossible for the user to go through Google's Street View function to check the townscape prepared in the Google Earth. For now, users have to use the layer control to show and close design alternatives on the map view as shown in Figure 6. Google Earth lacks support for simulating traffic, and it is difficult to support an avatar system using the current version of Google Earth. Users should ultimately set up another server to support an avatar system

It is important to note the pricing models of each software platform. VR-Cloud's cloud server software is commercially licensed, but its client interface is free to use by all viewers. Most Google Earth users interface with the free version, but the commercial Pro version of its cloud software offers essential planning tools absent from the free version. 3DVIA also offers a free version of its VR-Cloud server software and if users would like to use the full functionality of 3DVIA, it is necessary to pay.

\subsection{DVIA}

Unlike VR-Cloud and Google Earth, 3DVIA requires users to upload their models into its 3D warehouse. As show in Figure 7, it is possible to upload the models for the pedestrian bridge, buildings, and street furniture separately. However, it is also possible to upload the entire dataset to the 3D warehouse as one file.

Another difference between 3DVIA and the previous tools is that we can manipulate the layout of the bridge, 


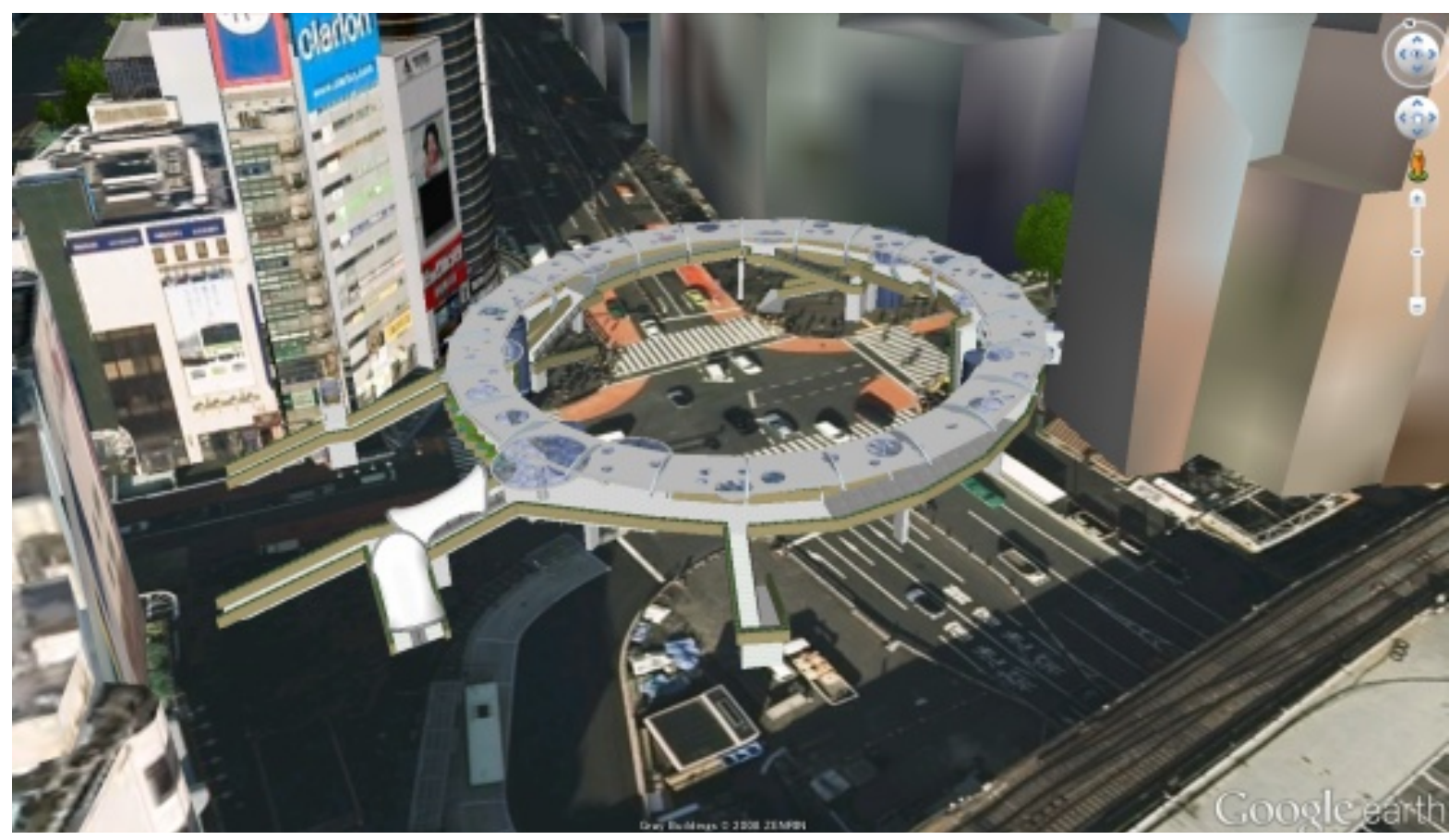

Figure 5. Bridge design in Google Earth V6.

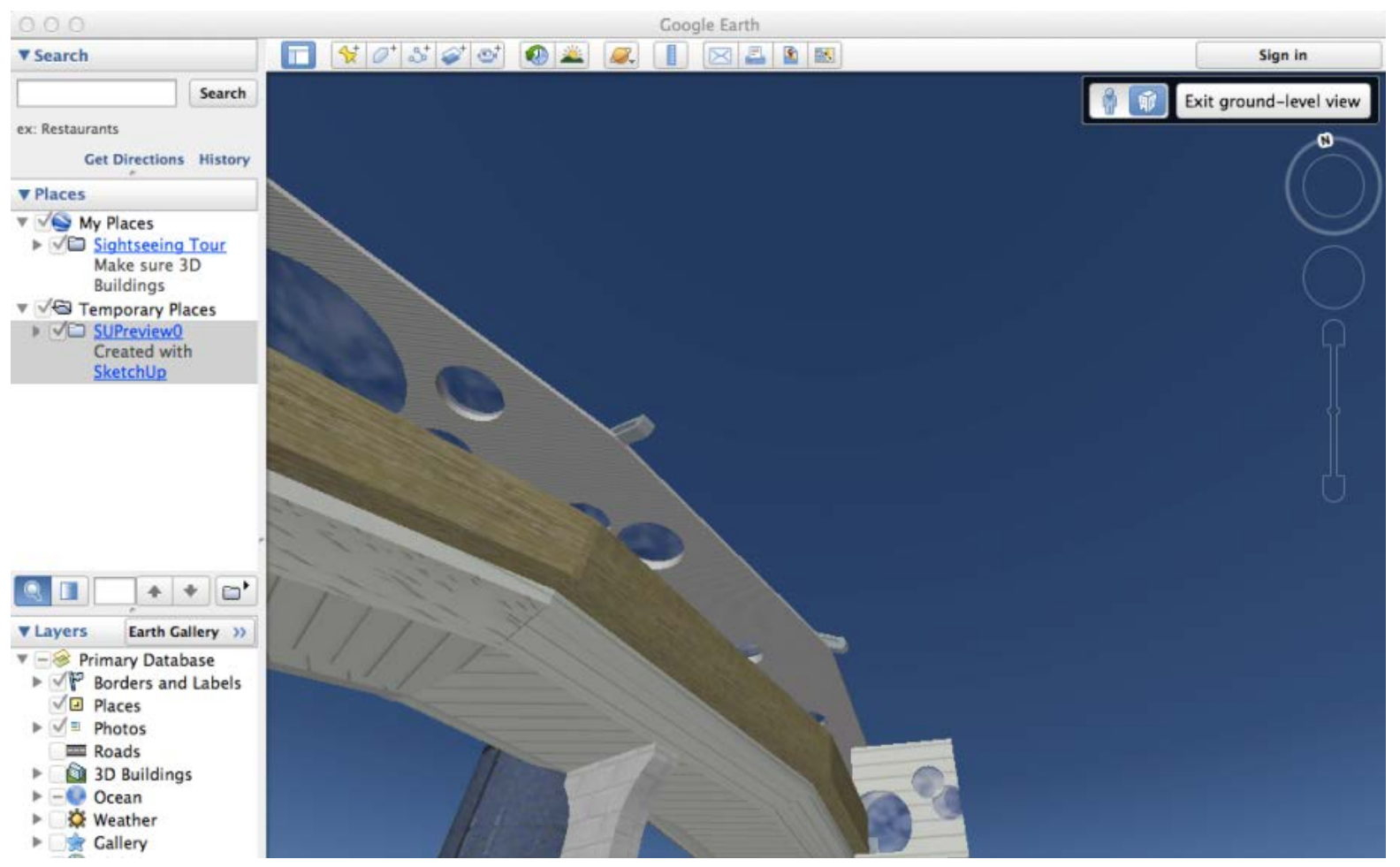

Figure 6. Interface in Google Earth.

street furniture, and buildings as shown Figure 8. Planners and designers can simultaneously adjust the design within the virtual world, which is an amazing feature of 3DVIA's cloud software service. In Figure 8, the user is locating a car. However, there are no programmable scenarios that can define the behaviors of cars like the function present in VR-Cloud. In 3DVIA, only the avatars representing real users will move around the virtual 


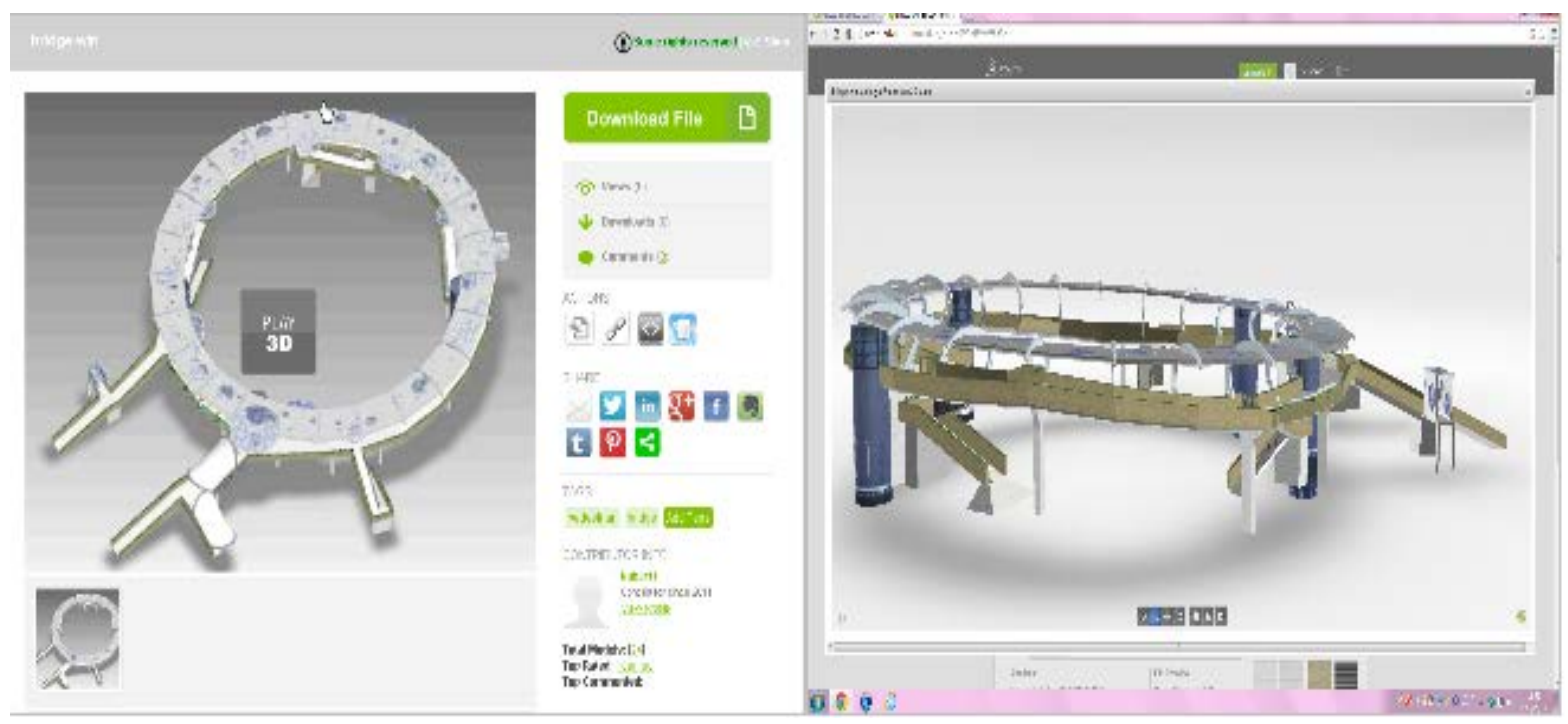

Figure 7. 3D model of bridge design uploaded to 3DVIA.

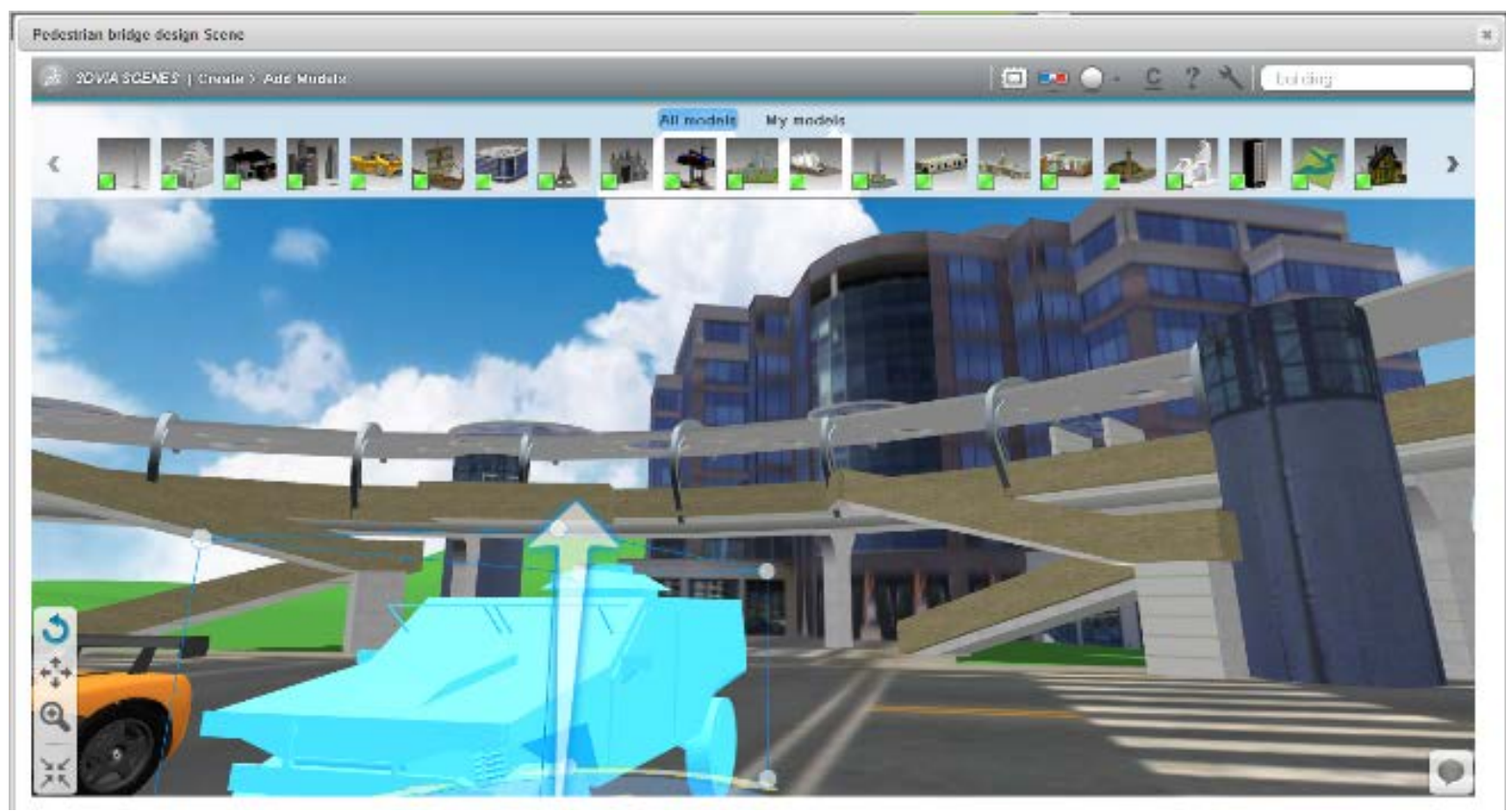

Figure 8. Multiuser environment of pedestrian bridge design using 3DVIA.

world for reviewing the design. It is possible for avatars to share the virtual world communicate through an Internet chat tool as shown as Figure 9. Despite its great collaboration features, 3DVIA is weak in processing large datasets.

Finally, we will summarize the differences between the VR-Cloud, Google Earth, and 3DVIA in Table 1. All three tools have a plenty of functionality in VR representation and visualization, VR-Cloud is strong in simulating behaviors of people and cars. Google Earth provides a strong planning experience in the context of a virtual Earth. 3DVIA provides convenience for user to adjust designs within the virtual world and communicate with other users over the Internet.

\section{Conclusions}

In this paper, we compared the functionality of cloud-based VR SaaS to propose and collaborate on design 


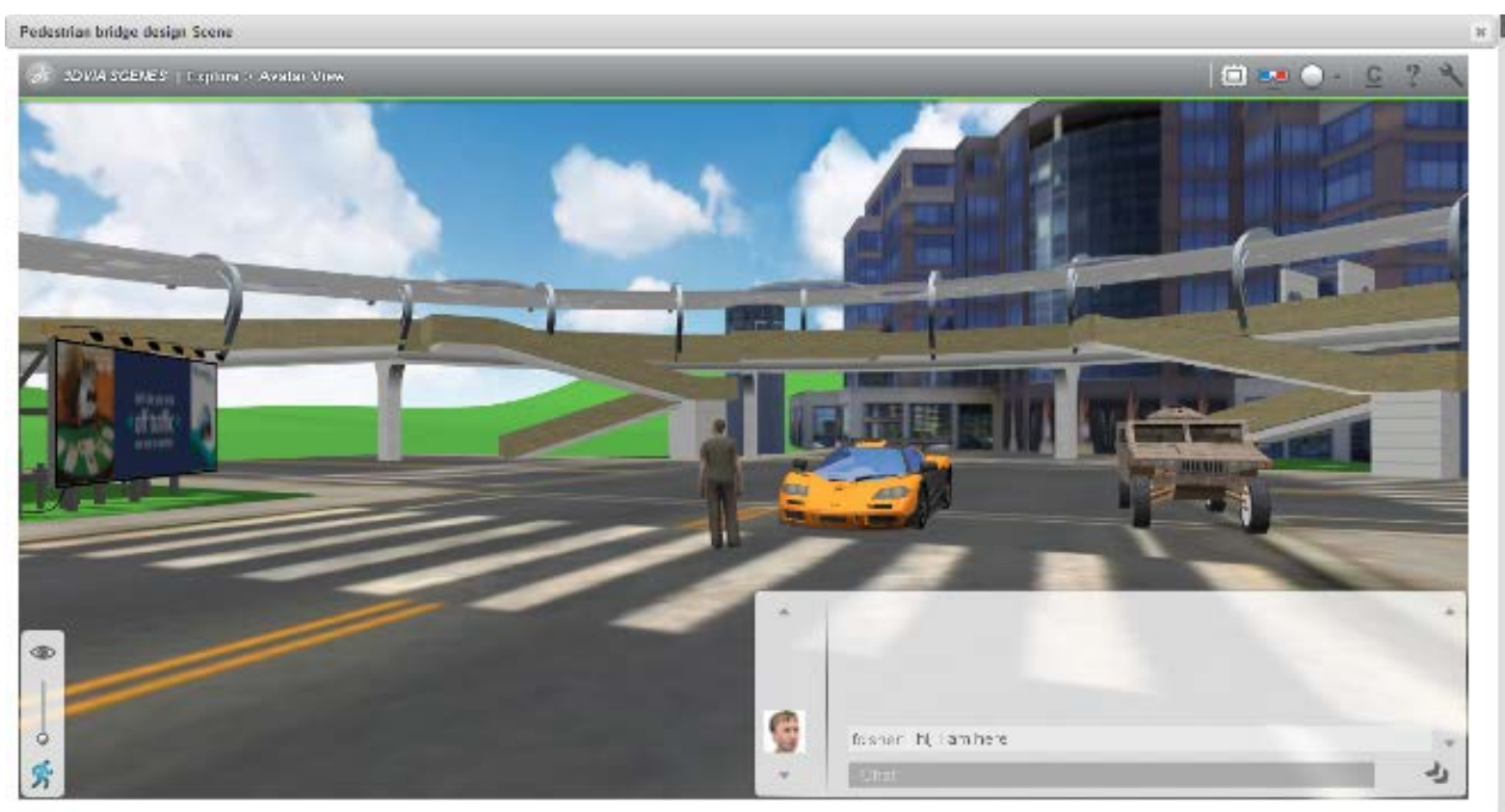

Figure 9. Multiuser environment for meeting using 3DVIA.

Table 1. Comparison of the SaaS of three platforms.

\begin{tabular}{|c|c|c|c|}
\hline & VR-Cloud & Google Earth & 3DVIA \\
\hline \multicolumn{4}{|l|}{ Server side } \\
\hline VR server & Application server & Application server & Application server \\
\hline Server management & $\begin{array}{l}\text { Server cluster } \\
\text { (with static IP addresses) }\end{array}$ & Cloud server & Cloud server \\
\hline \multicolumn{4}{|l|}{ VR database } \\
\hline Dataset & KMZ created in SketchUp & KMZ created in SketchUp & KMZ created in SketchUp \\
\hline VR objects & Prepared and imported & $\begin{array}{l}\text { Prepared locally and imported } \\
\text { Potential to use online data } \\
\text { warehouse }\end{array}$ & $\begin{array}{l}\text { Composed online using 3DVIA } \\
\text { tool with potential to upload to } \\
\text { online data warehouse }\end{array}$ \\
\hline VR data editing & Impossible & Impossible & Direction, position and scale \\
\hline Design alternatives & Prepared & Prepared & $\begin{array}{l}\text { Possible for users to adjust } \\
\text { in application }\end{array}$ \\
\hline Data range & Planning site only & Global & Planning site only \\
\hline Surrounding data & No & 3D warehouse & 3D warehouse \\
\hline \multicolumn{4}{|l|}{ Functions of the VR server } \\
\hline VR navigation & Predefined and free camera & Free camera & Predefined and free camera \\
\hline Built-in communication & No (QQ) & No (QQ) & Chat \\
\hline Avatars & $\begin{array}{l}\text { Car and person can move based } \\
\text { on programmed scenarios }\end{array}$ & No & $\begin{array}{l}\text { Avatars representing movement } \\
\text { of real users }\end{array}$ \\
\hline Sound environ. & Car noise & No & No \\
\hline \multicolumn{4}{|l|}{ Total evaluation } \\
\hline SaaS & VR representation and simulation & VR representation & $\begin{array}{l}\text { VR representation and } \\
\text { communication with avatars }\end{array}$ \\
\hline System developer & Difficult & Easy & Easy \\
\hline Planning features & Comprehensive & Simple & Middle \\
\hline
\end{tabular}


alternatives of a pedestrian bridge. In conclusion, cloud-based VR technology does support conventional design coordination and communication from a technical standpoint. In our study, we comprehensively evaluated the features of three tools: VR-Cloud, Google Earth and 3DVIA. 3DVIA is one kind of platform in supporting urban design and planning through virtual reality using cloud servers. Google Earth and VR-Cloud are strong platforms for users to share an accurate virtual globe representative of the real world or a programmed virtual environment, respectively.

It is impossible to compare all tools of interest in this field. For example, we do not take an on-line game engine like Unity3D as a case study. However, to further investigate the technical possibilities of effective communication and evaluation in urban planning using cloud-computing technology, we will evaluate on-line game engines in future research.

\section{References}

[1] Grozev, N. and Buyya, R. (2014) Inter-Cloud Architectures and Application Brokering: Taxonomy and Survey. Software: Practice and Experience, 44, 369-390. http://dx.doi.org/10.1002/spe.2168

[2] Buyya, R., Yeo, C.S., Venugopal, S., Broberg, J. and Brandic, I. (2009) Cloud Computing and Emerging IT Platforms: Vision, Hype, and Reality for Delivering Computing as the 5th Utility. Future Generation Computer Systems, 25, 599-616. http://dx.doi.org/10.1016/j.future.2008.12.001

[3] Farber, D. (2008) The New Geek Chic: Data Centers. CNET News, 2008-06-25.

[4] Chowdhury, G. (2012) Building Environmentally Sustainable Information Services: A Green IS Research Agenda. Journal of the American Society for Information Science and Technology, 63, 633-647. http://dx.doi.org/10.1002/asi.21703

[5] Grover, J. (2013) Android Forensics: Automated Data Collection and Reporting from a Mobile Device. Digital Investigation, 10, S12-S20. http://dx.doi.org/10.1016/j.diin.2013.06.002

[6] Ngai, E.C.-H. and Gunningberg, P. (2013) Quality-of-Information-Aware Data Collection for Mobile Sensor Networks. Pervasive and Mobile Computing, 11, 203-215. http://dx.doi.org/10.1016/j.pmcj.2013.07.012

[7] Michael, K. and Clarke, R. (2013) Location and Tracking of Mobile Devices: Uberveillance Stalks the Streets. Computer Law \& Security Review, 29, 216-228. http://dx.doi.org/10.1016/j.clsr.2013.03.004

[8] de Vries, N.J., Davel, M.H., Badenhorst, J., Basson, W.D., de Wet, F., Barnard, E. and de Waal, A. (2014) A Smartphone-Based ASR Data Collection Tool for Under-Resourced Languages. Speech Communication, 56, 119-131. http://dx.doi.org/10.1016/j.specom.2013.07.001

[9] Ma, X., Cui, Y. and Stojmenovic, I. (2012) Energy Efficiency on Location Based Applications in Mobile Cloud Computing: A Survey. Procedia Computer Science, 10, 577-584. http://dx.doi.org/10.1016/j.procs.2012.06.074

[10] Laurila, J.K., Perez, D.G., Aada, I., Bloma, J., Bornet, O., Dob, T.M.T., Doussea, O., Eberle, J. and Miettinen, M. (2013) From Big Smartphone Data to Worldwide Research: The Mobile Data Challenge. Pervasive and Mobile Computing, 9, 752-771. http://dx.doi.org/10.1016/j.pmcj.2013.07.014

[11] Whaiduzzaman, M., Sookhak, M., Gani, A. and Buyya, R. (2013) A Survey on Vehicular Cloud Computing. Journal of Network and Computer Applications, 40, 325-344.

[12] Huang, Q.Y., Yang, C.W., Liu, K., Xia, J.Z., Xu, C., Li, J., Gui, Z.P., Sun, M. and Li, Z.L. (2013) Evaluating OpenSource Cloud Computing Solutions for Geosciences. Computers \& Geosciences, 59, 41-52. http://dx.doi.org/10.1016/j.cageo.2013.05.001

[13] Guan, H.Y., Li, J., Zhong, L., Yu, Y.T. and Chapman, M. (2013) Process Virtualization of Large-Scale Lidar Data in a Cloud Computing Environment. Computers \& Geosciences, 60, 109-116. http://dx.doi.org/10.1016/j.cageo.2013.07.013

[14] Marques, R., Feijo, B., Breitman, K., Gomes, T., Ferracioli, L. and Lopes, H. (2013) A Cloud Computing Based Framework for General 2D and 3D Cellular Automata Simulation. Advances in Engineering Software, 65, 78-89. http://dx.doi.org/10.1016/j.advengsoft.2013.05.014

[15] Couclelis, H. (2005) “Where Has the Future Gone?” Rethinking the Role of Integrated Land-Use Models in Spatial Planning. Environment and Planning A, 37, 1353-1371. http://dx.doi.org/10.1068/a3785

[16] Jiao, Y., Zhang, S.H., Li, Y.K., Wang, Y.H. and Yang, B.M. (2013) Towards Cloud Augmented Reality for Construction Application by BIM and SNS Integration. Automation in Construction, 33, 37-47. http://dx.doi.org/10.1016/j.autcon.2012.09.018

[17] Hildebrandt, D. and Döllner, J. (2010) Service-Oriented, Standards-Based 3D Geovisualization: Potential and Challenges. Computers, Environment and Urban Systems, 34, 484-495.

http://dx.doi.org/10.1016/j.compenvurbsys.2010.05.003 
[18] Spickermann, A., Grienitz, V. and von der Gracht, H.A. (2013) Heading towards a Multimodal City of the Future? Multi-Stakeholder Scenarios for Urban Mobility. Technological Forecasting and Social Change. http://dx.doi.org/10.1016/j.techfore.2013.08.036

[19] Ghaemi, P., Swift, J., Sister, C., Wilson, J.P. and Wolch, J. (2009) Design and Implementation of a Web-Based Platform to Support Interactive Environmental Planning. Computers, Environment and Urban Systems, 33, 482-491. http://dx.doi.org/10.1016/j.compenvurbsys.2009.05.002

[20] Li, S.L. (2005) A Web-Enabled Hybrid Approach to Strategic Marketing Planning: Group Delphi + a Web-Based Expert System. Expert Systems with Applications, 29, 393-400. http://dx.doi.org/10.1016/j.eswa.2005.04.018

[21] Rao, M., Fan, G.L., Thomas, J., Cherian, G., Chudiwale, V. and Awawdeh, M. (2007) A Web-Based GIS Decision Support System for Managing and Planning USDA's Conservation Reserve Program (CRP). Environmental Modelling \& Software, 22, 1270-1280. http://dx.doi.org/10.1016/j.envsoft.2006.08.003

[22] Angeli, D. and Masala, E. (2012) A Cost-Effective Cloud Computing Framework for Accelerating Multimedia Communication Simulations. Journal of Parallel and Distributed Computing, 72, 1373-1385. http://dx.doi.org/10.1016/j.jpdc.2012.06.005

[23] Ma, Y., Shen, Z.J., Gao, X.L. and Dang, A.R. (2013) Synthesizing Service Resources in Support for Urban-Rural Planning: Status and Prospects. Progress in Geography, 32, 1670-1680.

[24] Sun, A. (2013) Enabling Collaborative Decision-Making in Watershed Management Using Cloud-Computing Services. Environmental Modelling \& Software, 41, 93-97. http://dx.doi.org/10.1016/j.envsoft.2012.11.008

[25] Bernhart, W., Grosse, K.P. and Hoffmann, M. (2011) Automotive Landscape 2025: Opportunities and Challenges Ahead. Roland Berger Strategy Consultants, Munich.

[26] Shen, Z.J. and Kawakami, M. (2010) An Online Visualization Tool for Internet-Based Local Townscape Design. Computers, Environment and Urban Systems, 34, 104-116. http://dx.doi.org/10.1016/j.compenvurbsys.2009.09.002

[27] Shen, Z.J. and Kawakami, M. (2007) Study on Visualization of Townscape Rules Using VRML for Public Involvement. Journal of Asian Architecture and Building Engineering, 6, 119-126. http://dx.doi.org/10.3130/jaabe.6.119

[28] Shen, Z.J., Lei, Z.H., Li, X.F. and Sugihara, K. (2013) Design Coordination Regarding Urban Design Guidelines Using Google Earth. International Review for Spatial Planning and Sustainable Development, 1, 53-68. http://dx.doi.org/10.14246/irspsd.1.3_53

[29] Shen, Z.J., Kawakami, M., Chen, Z.Y. and Peng, L.Q. (2012) Historical Landscape Restoration Using Google Technology in a Traditional Temple Area, Kanazawa, Japan. In: Geospatial Techniques in Urban Planning, Advances in Geographic Information Science, Springer, Berlin, 241-261. http://dx.doi.org/10.1007/978-3-642-13559-0_12 
Scientific Research Publishing (SCIRP) is one of the largest Open Access journal publishers. It is currently publishing more than 200 open access, online, peer-reviewed journals covering a wide range of academic disciplines. SCIRP serves the worldwide academic communities and contributes to the progress and application of science with its publication.

Other selected journals from SCIRP are listed as below. Submit your manuscript to us via either submit@scirp.org or Online Submission Portal.
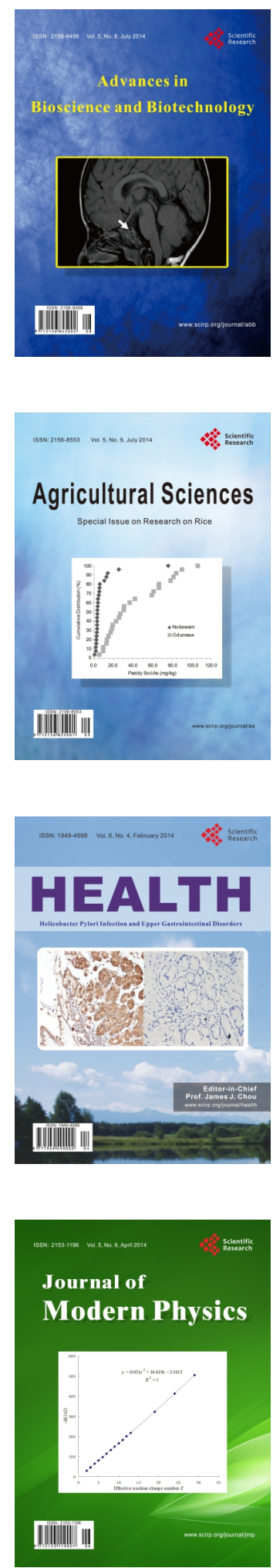
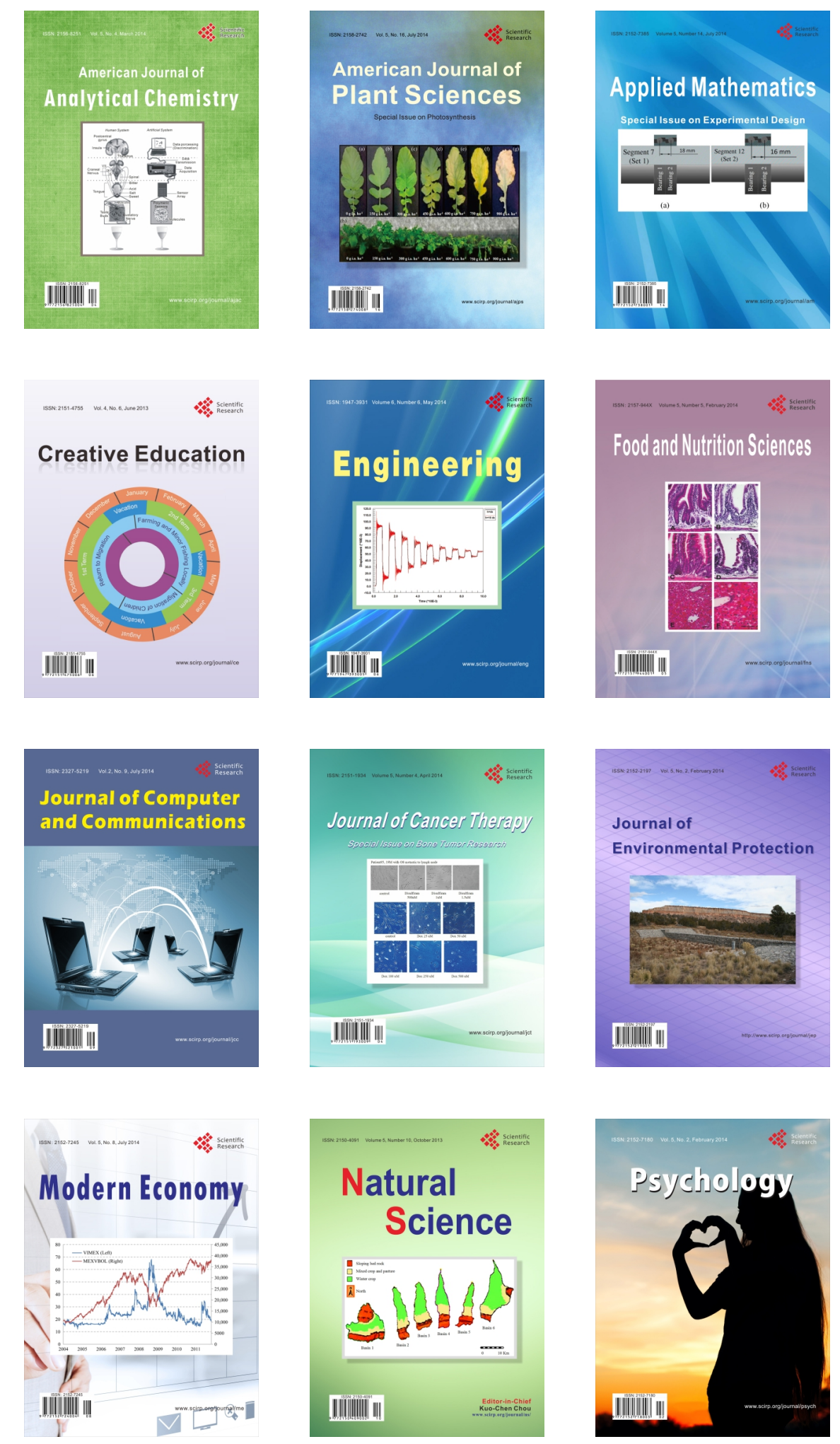